\title{
Measuring fractional forest canopy element cover and pÿopenness definitions and methodologies revisited
}

\section{Gonsamo, Alemu}

2013

Gonsamo , A , D'Odorico , P \& Pellikka , P 2013 , ' Measuring fractional forest canopy

pÿelement cover and openness definitions and methodologies revisited ' , Oikos, vol. 122 , no. 9 , pp. 1283-1291 . https://doi.org/10.1111/j.1600-0706.2013.00369.x

http://hdl.handle.net/10138/44809

https://doi.org/10.1111/j.1600-0706.2013.00369.x

publishedVersion

Downloaded from Helda, University of Helsinki institutional repository.

This is an electronic reprint of the original article.

This reprint may differ from the original in pagination and typographic detail.

Please cite the original version. 
Oikos 122: 1283-1291, 2013

doi: $10.1111 / j .1600-0706.2013 .00369 . x$

(C) 2013 The Authors. Oikos (C) 2013 Nordic Society Oikos

Subject Editor: Bente Graae. Accepted 21 April 2013

\title{
Measuring fractional forest canopy element cover and openness - definitions and methodologies revisited
}

\author{
Alemu Gonsamo, Petra D'Odorico and Petri Pellikka \\ A. Gonsamo (gonsamoa@geog.utoronto.ca) and P. Pellikka, Dept of Geosciences and Geography, Univ. of Helsinki, PO Box 64, FIN-00014 \\ Helsinki, Finland. AG also at: Dept of Geography and Program in Planning, Univ. of Toronto, Toronto, ON, M5S 3G3, Canada. \\ - P. D’Odorico, Remote Sensing Laboratories, Dept of Geography, Univ. of Zurich, Winterthurerstr 190, CH-8057 Zurich, Switzerland.
}

\begin{abstract}
Canopy structural parameters are often used to give adequate representation of vegetated ecosystems for various purposes including primary productivity, climate system, water and carbon gas exchanges, and radiation extinction. Canopy structural parameters are usually described using several pseudo-synonymous terms, often measuring different components of vegetation canopies. Standardization in the definitions has fallen short, leading to confusion of terms even in standard text books making the comparison of historic measures futile. Here we clarify concepts that have been used for fractional canopy element cover and openness measures. The fractional canopy element cover and openness concepts considered are canopy closure, canopy cover, canopy openness, crown closure, crown completeness, crown cover, crown porosity, site openness and tilt openness. New methodologies are presented to obtain large scale fractional canopy element cover and openness measures using hemispherical photography. The new methodologies and variations in definitions of fractional canopy element cover and openness concepts are demonstrated using photographic measurements in complex topography. The results indicate that both fractional canopy element cover and openness parameters can be estimated with a few point-based measurements using hemispherical photography. Hemispherical photography is therefore less time, labour and resource intensive, as compared to point based measuring techniques of canopy element cover and openness.

Most of the commonly and interchangeably used concepts of fractional canopy element cover and openness measures represent physically different structural properties of a vegetated ecosystem.
\end{abstract}

Leaf level analyses of plant canopies provide many insights into plant adaptation and processes to the environment; however, integration with crown and canopy level processes is essential to analyse vegetated environments and their productivities at regional and global scales. Canopy structural parameters are often used to give adequate representation of vegetated ecosystems for purposes ranging from primary productivity, climate system, water and carbon gas exchanges, and radiation extinction (Bréda 2003, Middelboe and Binzer 2004, Kulakowski et al. 2011, Yuan et al. 2012). The geometric approach to canopy structure seeks to quantify the area, pattern and orientation of organs such as leaves, trunks, flowers and fruits, and the size, morphology and dispersion of gaps which separate them (Campbell and Norman 1990, Monteith and Unsworth 1990). The statistical analyses of these properties reduces data to a few synthetic geometrical descriptors such as fractional canopy element cover and

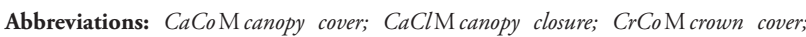
CrClM crown closure; $\mathrm{CrCom} \mathrm{M}$ crown completeness; $P_{0} \mathrm{M}$ gap fraction; $C O \mathrm{M}$ canopy openness; SOM site openness; TOM tilt openness; FSM fractional soil; CPM crown porosity; HPM hemispherical photography. openness parameters, which can be successfully related with the key component of physiological, climatological and biogeochemical processes.

Here we define plant crown as the totality of the plant's aboveground parts, including stems, leaves, and reproductive structures, whereas plant canopy is the aboveground portion of a plant community, formed by plant crowns. Crown or canopy dimensions relative to the land beneath the vegetation are well established measures of the development, definition and status of for example forest stands. The Food and Agriculture Organization (FAO) defines forest based on the canopy cover, as land of at least 0.5 ha with potential canopy cover over $10 \%$ and potential tree height of at least $5 \mathrm{~m}$ (FAO 2001). This definition has been used and adapted in many European National Forest Inventories (Tabacchi et al. 2007, Winter et al. 2008). One of the main difficulties in determining fractional canopy element cover or openness is the absence of commonly accepted precise definitions for these concepts (Sarvas 1954, Kuusipalo 1985, Bunnell and Vales 1990, Ganey and Block 1994, Nuttle 1997). Vegetation cover is often described based on synonymous terms, such as canopy cover, canopy closure, crown cover or crown closure, often measuring different components of vegetation canopies. 
Previous studies have stressed the importance of the definitions of vegetation cover (Jennings et al. 1999, Rautiainen et al. 2005, Korhonen et al. 2006, Wilson 2011). Jennings et al. (1999) distinguish two structural quantities for measuring forest canopies. The first is the canopy closure defined as the proportion of sky hemisphere obscured by vegetation. In this particular study however canopy closure is set equal to canopy density. The second measure is canopy cover, defined as the proportion of the forest floor covered by the vertical projection of tree crowns. This definition fails to clarify whether the gaps inside the tree crowns are counted as canopyit follows that determining the outer envelope of a crown becomes elusive. Rautiainen et al. (2005) and Korhonen et al. (2006) further detailed the differences of canopy cover and closure, including what constitutes a plant canopy. However, standardization in the definitions of canopy cover and openness measures has fallen short, leading to confusion of terms even in standard text books (Avery and Burkhart 1994, Philip 1994) and comparison of different canopy components as if representing the same measure (Ganey and Block 1994).

To this date, the lack of consistent definitions and explicit descriptions encountered in the literature has made the comparison of historic measures futile. Standardized definitions of fractional canopy element cover and openness concepts are critical to ensure compatibility of international forestry statistics, monitoring of forest stand development and comparison of measurements from various groups. Therefore, this study aims at establishing standardised definitions of fractional canopy element cover and openness measures. New methodologies are presented to obtain large scale fractional canopy element cover and openness measures using hemispherical photography. The new methodologies and variations in definitions of fractional canopy element cover and openness concepts are demonstrated using photographic measurements in complex topography. The case study is deliberated to highlight the differences of various fractional canopy element cover and openness measures based on the increasingly popular in situ instrument, hemispherical photography.

\section{Hemispherical photography for determination of fractional canopy element cover and openness}

Hemispherical photography (HP) is often used for leaf area index (LAI) and light regime determination in forest canopies (Hill 1924, Rich 1990). The use of HP for fractional canopy element cover and openness determination is often hampered by theoretical and practical difficulties. Therefore, exploring the potential of using larger view zenith angle HP measurements for large scale estimations of the nadir fractional canopy element cover and openness measures are a further objective of this study.

HP, also known as fisheye or canopy photography is a technique to estimate solar radiation and plant canopy structure using photographs taken looking upward through an extreme wide-angle lens (Hill 1924, Rich 1990). Typically, the viewing angle approaches or equals $180^{\circ}$, such that all sky directions are simultaneously visible. The resulting photographs record the geometry of visible sky, or conversely the geometry of sky obstruction by silhouette canopy elements or other near-ground features such as topography. HP produces a continuous 2D spatial record of the canopy environment (sky, canopy elements and topography). Above and beyond, due to its large footprint, HP covers large sampling areas which would otherwise require labour intensive work to cover by other point based measuring techniques (e.g. rods, wheel spokes, plum bobs, cross wires, lasers and fibre optics: Wilson 2011). The point based in situ instrumentation for measuring 2D metrics of fractional canopy element cover and openness are discussed in other literature (Jennings et al. 1999, Korhonen et al. 2006, Paletto and Tosi 2009).

HP and other point based canopy cover and openness techniques are used as reference ground measures to evaluate LiDAR (light detection and ranging) and other air- and space-borne remote sensing estimates (Carreiras et al. 2006, Ko et al. 2009, Gonsamo et al. 2011a, Korhonen et al. 2011). Air- and space-borne remote sensing methods are applied for fractional canopy element cover and openness determination on landscape level. These methods are based on differences in spectral reflectances between vegetation and other land surface components (Carreiras et al. 2006, Ko et al. 2009, Gonsamo et al. 2011a). Terrestrial and airborne LiDAR are increasingly being used to estimate forest parameters including canopy cover and openness. LiDAR systems have been shown to be suitable for providing not only horizontal information on the forest canopy structure, but also explicit vertical information due to the canopy penetration capability of the emitted signal (Leeuwen and Nieuwenhuis 2010, Kaartinen et al. 2012, Lindberg et al. 2012). The description of these techniques however falls out of the scope of this paper.

Figure 1 shows the typical projection of an HP on a plane. Gap fraction $\left(P_{0}\right)$, i.e. the relative proportion of open sky contained on the projected image plane over a given area, is computed from a digital image classified into black (canopy element) and white (sky or topography in the case of sloping ground) (Fig. 2). The $P_{0}$ is usually derived from a portion of hemisphere grid defined by the midpoint of zenith angle $(\theta)$ and azimuth angle $(\phi)$, or concentric rings of zenithal annuli defined by the midpoint of $\theta$ (Fig. 1, 2; Gonsamo et al. 2010). The canopy height above the HP sensor is usually referred to as a unit of canopy element

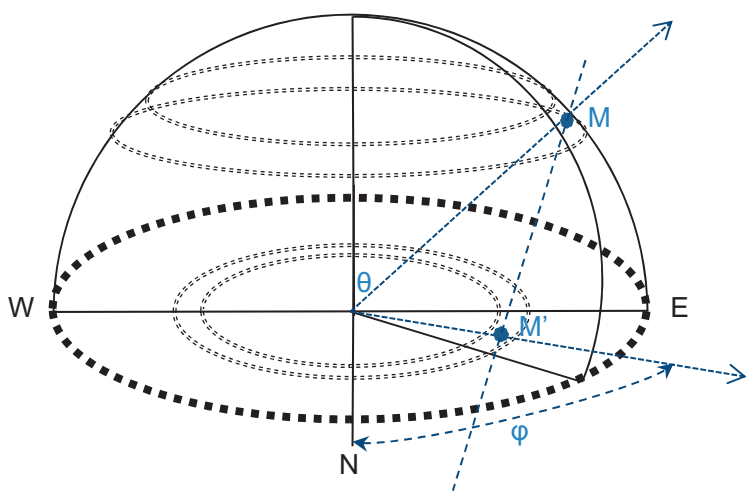

Figure 1 . The projection as seen with a hemispherical lens looking upward. Hemispherical lens projects a hemisphere of directions on a plane. Point $\mathrm{M}$ on the hemisphere is projected on a plane as point M'. Each sky direction can be represented by unique angular coordinates, usually by a midpoint of zenith angle $\theta$ and a midpoint of azimuth angle $\varphi$. 

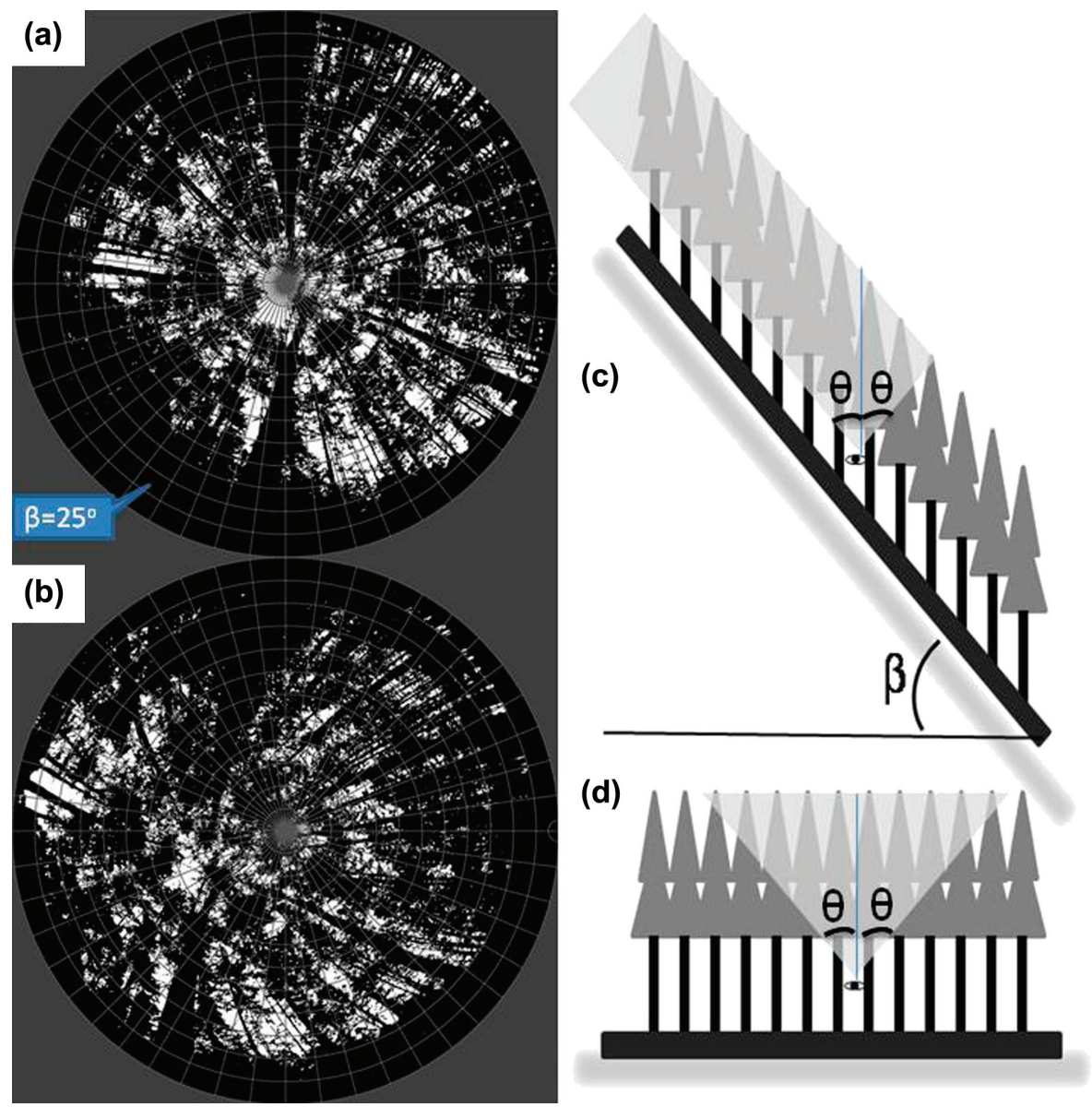

Figure 2. Examples of thresholded levelled (a) and tilted (b) hemispherical photographs on sloping ground for the same photo point. The circular rings represent the zenithal division (zenithal annuli) and the radial lines represent the azimuthal divisions resulting in a portion of hemisphere grid for gap fraction extraction. (c) the variations of the path length illustrated on bi-directional base on sloping ground, and (d) the same bi-directional path length on leveled ground. $\theta$ is zenith angle, and $\beta$ slope angle.

depth. Therefore, $P_{0}$ at a nadir angle $(\theta=0)$ represents the fractions of unobstructed sky for a unit depth of a canopy element. At non-nadir angle measurements, i.e. for larger zenith angles, the $P_{0}$ should be normalized to unity of canopy element depth by dividing by the cosine $\theta$ (Gonsamo et al. 2010). This is due to a larger path length, i.e. distance of penetration of a ray of light through a canopy when measured at larger $\theta$. This is straight forward for forest canopies on leveled ground since the path length is identical at all azimuth angles for a given zenith angle over the hemisphere. On sloping ground, the range of path lengths increases for the hemispherical sensor held horizontally (leveled acquisition) for a given zenith angle. As a result, the forest canopy appears denser upslope in the HP and lighter downslope for the same zenith angle (Fig. 2). To normalize the $P_{0}$ to unity of canopy element depth, the slope angle should be incorporated (Walter and Torquebiau 2000, Gonsamo and Pellikka 2008).

Although HP provides a simultaneous acquisition of $P_{0}$ over the entire hemisphere, there are always theoretical and practical difficulties on sampling the useful hemisphere regions (Gonsamo et al. 2010). Hemisphere regions close to nadir $\left(\theta=0^{\circ}\right)$ are affected by sampling and optical errors (e.g. strong forward sun scattering on lens and on sensor from overhead canopy openings making it difficult to extract canopy and sky pixels). Whereas, those close to the horizon $\left(\theta=90^{\circ}\right)$ are also affected by sampling and optical errors such as: insufficient viewable $P_{0}$, coarse pixel resolutions, blocking from tree trunks, multiple scattering, lens vignetting, and blurring, to mention a few. This poses difficulties to obtain a reliable canopy cover estimate from nadir zenith angles only. The placing of the hemispherical camera set is often chosen to be on open areas within the forest stand far away from tree trunks, thus resulting in large nadir opening. It is practically not possible to acquire HP pointing the nadir to the centre of the crown envelope. The $P_{0}$ from a hemisphere region above $60^{\circ}$ zenith angle is usually deemed to be less useful for canopy structure estimates (Gonsamo et al. 2010). Here, we present new sets of methodologies for large scale estimations of fractional canopy element covers and openness from useful hemisphere regions.

\section{Definitions of fractional canopy element cover and openness}

The following sections provide standardised definitions and measures of fractional canopy element cover and openness. The term canopy elements ( $\cong$ phytoelements) includes needles, leaves, flowers, fruits, cones, branches and trunks as used throughout the paper. The main focus lies on 
estimates based on the gap fraction $\left(P_{0}\right)$ method as derived from hemispherical sensors. The estimates of the fractional cover and openness are for the overstorey part of the vegetation therefore anything below (usually under breast height $1.3 \mathrm{~m}$ ) is considered as open (consisting of soil and/or understorey).

\section{Definitions of fractional canopy element cover}

\section{Canopy cover (CaCo)}

Canopy cover $(\mathrm{CaCo})$ is defined as the proportion of horizontal vegetated area occupied by the vertical projection of canopy elements. The measurements should be made in exact vertical direction and the canopy elements should not comprise the within crown gaps. The term canopy cover can be expressed with other equivalent terms such as vegetation fractional cover, vegetation cover, canopy coverage (American English usage), or fractional vegetation cover. $\mathrm{CaCo}$ is a measure that reflects the dominance of a site by trees or by a particular species of tree. In the following, $\mathrm{CaCo}$ is obtained following different methods depending on the type of $P_{0}$ measurement.

From a nadir zenith angle gap fraction $\left(P_{0}\right)$ measurement:

$\mathrm{CaCo}=1-P_{0}$

From a single non-nadir zenith angle $P_{0}$ measurement:

$\mathrm{CaCo}=1-\exp \left(\ln \left(P_{0}(\theta)\right) \cos \theta\right)$

From multiple zenith angle $P_{0}$ measurements:

$$
\mathrm{CaCo} \approx 1-\frac{\sum_{\theta=i}^{\theta=j} \exp \left(\ln \left(p_{0}(\theta)\right) \cos \theta\right) \sin \theta \mathrm{d} \theta}{\sum_{\theta=i}^{\theta=j} \sin \theta \mathrm{d} \theta}
$$

where $P_{0}$ is gap fraction, and $i$ and $j$ are the lower and upper zenith angles of a sphere's segment, respectively. The term $\cos \theta$ is used to project the gap fraction onto nadir zenith angle, i.e. normalize path length to a unity and $\sin \theta$ $d \theta$ is the numerical integral term used for hemispherical sensors to give weights of measurement to their respective spatial area.

From a single non-nadir zenith angle $P_{0}$ measurement for known $G$ (the mean projection of the unit canopy element area to the plane normal to the direction $\theta$ ) and $\Omega$ (canopy element clumping index, quantifying the deviation of canopy elements from random distribution) at that non-nadir zenith angle $\theta$ :

$$
\mathrm{Caco} \approx 1-\exp \left(\ln \left(p_{0}(\theta)\right) \frac{\mathrm{G}(\theta=0) \Omega(\theta)}{\mathrm{G}(\theta) \Omega(\theta=0)} \cos \theta\right)
$$

$G$ can be estimated from directional HP $P_{0}$ measurements (Pisek et al. 2011), whereas $\Omega$ can be estimated using gap fraction averaging or gap size distribution theories based on HP $P_{0}$ (Gonsamo and Pellikka 2009). Equation 4 gives more accurate $\mathrm{CaCo}$ estimate if the $G$ and $\Omega$ are known with great accuracy. Accurate measurement of $\mathrm{CaCo}$ involves practical and theoretical difficulties. $\mathrm{CaCo}$ is traditionally based on the point probe measurements looking exactly at a vertical direction. Large amounts of measurements are required to make representative estimates at plot, stand and landscape scales from point based measurements (e.g. 200-250 point measurements for unbiased estimate: Johansson 1985, Jennings et al. 1999, Rautiainen et al. 2005). Disadvantages of point based methods include the usually high bias of these measurements due to large spatial variability, time consuming field work, and measurements can only be performed far away from tree trunks. The new methods shown particularly in Eq. 2 and 3 are proposed to circumvent these problems using hemispherical sensors and converting the path length to a unity of the vertical projection coupled with appropriate spatial sampling weight of the view sectors.

\section{Canopy closure $(\mathrm{CaCl})$}

Canopy closure $(\mathrm{CaCl})$ : is the proportion of the sky hemisphere $\left(180^{\circ}\right)$ obscured by canopy elements when viewed from a single point. Theoretically, it should be expressed over the whole hemisphere, but measurements are often made for restricted selected zenith angles as gaps and canopy elements near the horizon are not practical to measure. $\mathrm{CaCl}$ is directly related to the light regime and microclimate, therefore affecting plant growth and survival at the point of measurement. $\mathrm{CaCl}$ calculations both on horizontal and sloping grounds are described in detail as a complement value of a unity of canopy openness.

\section{Crown cover (CrCo)}

Crown cover $(\mathrm{CrCo})$ is generally defined as a physical measurement of the sum of tree crown vertical projection areas divided by the horizontal area of observation unit the trees are growing on. The crown area is the outermost perimeter (envelope) of the crowns that form part of the upper canopy level (dominant and (or) co-dominant stratum). The variants of CrCo should be explicitly accompanied because of the within crown gaps and crown overlapping phenomena. There are four measures of $\mathrm{CrCo}: 1)$ the sum of vertically projected crown envelopes including within crown gaps counting the overlapping crown area once; 2 ) the sum of vertically projected crown envelopes including within crown gaps and overlapping crown area; 3 ) the sum of vertically projected crown envelopes without within crown gaps counting the overlapping crown area once; and 4) the sum of vertically projected crown envelopes without within crown gaps and including the overlapping crown area. 3) is essentially the same as Canopy cover. $\mathrm{CrCo}$ is directly related with stand density and species competition.

\section{Crown closure $(\mathrm{CrCl})$}

Crown closure $(\mathrm{CrCl})$ is an ecological term describing the development of a forest stand. It describes the dynamic process implying growth, age and mortality of trees. Stands can be said to be 'closed' to recruitment of new trees and still remain at low canopy cover. Unlike $\mathrm{CrCo}$ and $\mathrm{CaCl}$, the $\mathrm{CrCl}$ is related with the process while the former two are related with the condition. Typical measures of $\mathrm{CrCl}$ include 'open' and 'closed' forest, which are qualitatively determined by development of forest stand in relation to available site resources, age and mortality. 


\section{Crown completeness (CrCom)}

Crown completeness (CrCom) is another term introduced by Bunnell et al. (1985) and Vales and Bunnell (1985) to address wider zenith angle measurements of canopy cover. It is defined as the proportion of sky obstructed by vegetation within a defined angle from a single point. The present authors believe that this term and measure is obsolete because it has neither biological significance nor physical impact as it consists of an arbitrarily defined zenith angle, which will not be deduced from either vertical projection or complete hemispherical measures.

\section{Definitions of fractional vegetation openness}

\section{Gap fraction $\left(\mathbf{P}_{0}\right)$}

Gap fraction $\left(P_{0}\right)$ is the fraction of open sky not obstructed by canopy elements over the implied area defined by specific view zenith $(\theta)$ and azimuth $(\phi)$ angles (Fig. 1, 2). $P_{0}$ measurements provide information on the structure of a vegetation canopy, often parameterized with the leaf area index (LAI) and the leaf angle distribution. There is always an implied area over which $P_{0}$ is taken (Fig. 1; Gonsamo et al. 2010, 2011b).

\section{Canopy openness (CO)}

Canopy openness (CO) is the area fraction of the sky hemisphere $\left(180^{\circ}\right)$ that is unobstructed by canopy elements when viewed from a single point. $\mathrm{CO}$ is computed from the hemispherical sensors only (Hill 1924, Rich et al. 1993), and does not take the influence of the surrounding topography into account. Canopy openness is a complement in unity of canopy closure $(\mathrm{CO}=1-\mathrm{CaCl})$. $\mathrm{CO}$ is an indicator of potential daily penetration of solar radiation (Rich et al. 1993). In the following, CO is obtained through different methods depending on the topography and type of $P_{0}$ measurements.

On horizontal ground surface from full view hemispherical measurements:

$\mathrm{CO}=\int_{0}^{\pi / 2} P_{0}(\theta) \sin \theta \mathrm{d} \theta$

On horizontal ground surface from selected range of zenith angle measurements:

$\mathrm{CO} \approx \frac{\sum_{\theta=i}^{\theta=j} P_{0}(\theta) \sin \theta \mathrm{d} \theta}{\sum_{\theta=i}^{\theta=j} \sin \theta \mathrm{d} \theta}$

On sloping ground surface from full view hemispherical measurements:

$\mathrm{CO} \approx \frac{\sum_{\theta=i}^{\theta=j} P_{0}(\theta) \sin \theta \mathrm{d} \theta \mathrm{d} \varphi}{\sum_{\theta=i}^{\theta=j} \sin \theta \mathrm{d} \theta \mathrm{d} \varphi} \approx \frac{\sum_{\theta=i}^{\theta=j} P_{0}(\theta) \omega(\theta, \varphi)}{\sum_{\omega=i}^{\omega=j} \omega(\theta, \varphi)}$

The sphere segment which is determined from the intersections of $\theta$ and $\varphi$ facing skyward (above horizon) without topographic interference is used for CO determination over sloping ground. Therefore, the appropriate term for weighting the sphere segments is using the solid angle $(\omega)$ which is defined by the zenith and azimuth angles.

\section{Site openness (SO)}

Site openness (SO) is the area fraction of the sky hemisphere $\left(180^{\circ}\right)$ that is unobstructed by vegetation and topography when viewed from a single point. SO and $\mathrm{CO}$ are essentially the same for horizontal ground. On sloping ground, only the whole hemisphere measurements are valid to calculate SO. In the following, $\mathrm{SO}$ is obtained through different methods depending on the type of $P_{0}$ measurements.

Both on horizontal and sloping ground surface from full view hemispherical measurements:

$\mathrm{SO}=\int_{0}^{\pi / 2} P_{0}(\theta) \sin \theta \mathrm{d} \theta$

Both on horizontal and sloping ground surface from selected range of zenith angle measurements:

$\mathrm{SO} \approx \frac{\sum_{\theta=i}^{\theta=j} P_{0}(\theta) \sin \theta d \theta}{\sum_{\theta=i}^{\theta=j} \sin \theta d \theta}$

\section{Tilt openness (TO)}

Tilt openness (TO) this is a new index introduced in this paper to calculate the site openness including the openness below the horizontal datum by tilting the zenith reference of hemispherical view towards normal to slope direction (Gonsamo and Pellikka 2008). TO can be a complementary estimate for $\mathrm{CO}$ or $\mathrm{SO}$ particularly in vegetation growing on sloping ground where deep cloud cover is more prevalent throughout the growing season. In such cases, canopy openings below the horizon of the downslope side may contribute to the light availability of a point under the canopy. TO can be obtained only by hemispherical sensors (e.g. hemispherical photography, pyranometer) by tilting the lens or sensor parallel to the slope. TO can be calculated using the zenith angles of tilted acquisitions of hemispherical measurements (Gonsamo and Pellikka 2008):

$\mathrm{TO}=\int_{0}^{\pi / 2} P_{0}(\theta) \sin \theta d \theta$

$\mathrm{CO}, \mathrm{SO}$ and $\mathrm{TO}$ are equivalent measures for vegetation growing on the levelled ground.

\section{Fractional soil (FS)}

Fractional soil (FS) is defined as the proportion of ground area that is unobstructed by the vertical projection of canopy elements. The measurements are made in exact vertical direction. Fractional soil is a complement in a unity of canopy cover $(\mathrm{FS}=1-\mathrm{CaCo})$.

\section{Crown porosity (CP)}

Crown porosity $(\mathrm{CP})$ is the proportion of sky that is unobstructed by vegetation elements within crown envelopes in relation to the proportion of crown cover (Kucharik et al. 1999). The value of CP can be described as the normalized within crown gap fraction and is mainly related with the canopy element density. CP is calculated as gap fraction within crown envelope divided by crown cover ( $\mathrm{CrCo}$ (a)). CP is mostly used to calculate spatial distribution of canopy elements (Kucharik et al. 1999). 


\section{Case study of fractional canopy element cover and openness determinations in forest canopies growing on sloping ground}

\section{Data and methods}

Hemispherical photographs were acquired from the forest fragments growing on sloping ground (3-27०) of Taita Hills, southeast Kenya $\left(03^{\circ} 15^{\prime}\right.$ to $3^{\circ} 30^{\prime} \mathrm{S}$, and $38^{\circ} 15^{\prime}$ to $\left.38^{\circ} 30^{\prime} \mathrm{E}\right)$. The details of the study site description can be found in Gonsamo and Pellikka (2008). The sampling design was setup to include contrasting forest types, including natural tropical cloud forest with dense overstorey $(\mathrm{n}=24)$, dense understorey $(\mathrm{n}=19)$ and sparse overstorey $(\mathrm{n}=7)$, and Pinus $(\mathrm{n}=9)$, Cupressus $(\mathrm{n}=11)$ and Eucalyptus spp. $(\mathrm{n}=7)$ plantations. Dense overstorey represents the undisturbed natural tropical cloud forest. Dense understorey represents recently disturbed (clear cutting of overstorey trees), whereas sparse overstorey represents disturbed natural tropical cloud forest with selective cutting. Both dense understorey and sparse overstorey plots are characterised by tall and tick lianas, vines and tree seedlings. Subsets of the acquired HP were selected based on a minimum interference of slope in the photographs. The photographs were acquired using an 8 mega pixel digital camera equipped with a fish-eye lens adapter. Two types of HP were taken from each sampling point: 1) normal to a horizontal surface (optical axis oriented to local zenith), i.e. 'levelled' acquisition; and 2) normal to the slope of the ground (fish-eye lens oriented parallel to slope), i.e. 'tilted' acquisition (Gonsamo and Pellikka 2008). To separate sky from foliage, an automated well-known global Ridler and Calvard threshold (Ridler and Calvard 1978) was used in order to avoid subjective decision of the operator, for both levelled and tilted acquisitions using ImageJ software (US Natl Inst. of Health, Bethesda, Maryland, USA, $<$ imagej.nih.gov/ij/>, 1997-2012). All photographs were pre-processed prior to the image analysis. The pre-processing included orienting the photographs, centring (identifying the circular limit or horizon of the photograph), selection of appropriate colour channel (in this case blue channel, in order to improve the contrast between vegetation and sky), defining the threshold. All photographs were analysed using CIMES software (CIMES-FISHEYE, HEMISPHERICAL PHOTOGRAPHY OF FOREST CANOPIES, Strasberg, France) in order to extract oriented gap fractions (Gonsamo et al. 2011b). The canopy element cover and openness parameters were retrieved from oriented gap fractions using CIMES programs and in-house-developed Excel macro written in VBA (Visual Basic for Applications). Currently, all the new methodologies developed in this study are being incorporated into CIMES software packages of programs. With the exception of tilt openness which was calculated from tilted acquisition, all other parameters were calculated from levelled acquisition. LAI was estimated from the same HP using Campbell ellipsoidal distribution function of leaf angles and corrected for slope as detailed in Gonsamo and Pellikka (2008).

\section{Results and discussion}

As explained in the definitions section, accurate CaCo measurements pose theoretical and practical challenges since a large amount of point based measurements are required to achieve representative estimates. In the absence of independent fractional canopy element cover and openness measurements, the key criteria to evaluate the performances of the new methodologies is the invariance of estimates to zenith angles. This allows unbiased estimates with few HP measurements. The results shown in Fig. 3 indicate that the large scale approach proposed in this study is promising to achieve spatially representative $\mathrm{CaCo}$ measurements. Particularly, the results obtained based on Eq. 3 (Fig. 3b) show that $\mathrm{CaCo}$ can be estimated by integrating larger view zenith angles and correcting the path length based on the cosine angles. Once the integrated zenith angle surpasses $30^{\circ}$, all estimates of fractional canopy element cover and openness become stable, meaning that the addition of more sample areas does not affect the results giving coherent estimates with fewer number of HPs. Figure 4 presents the detailed estimates of several fractional canopy element cover and openness measures whereas Table 1 gives their statistical relationships. Figure $4 \mathrm{~b}$ further shows that there are only minor differences among $\mathrm{CO}, \mathrm{SO}$ and $\mathrm{TO}$ estimates per forest site mainly due
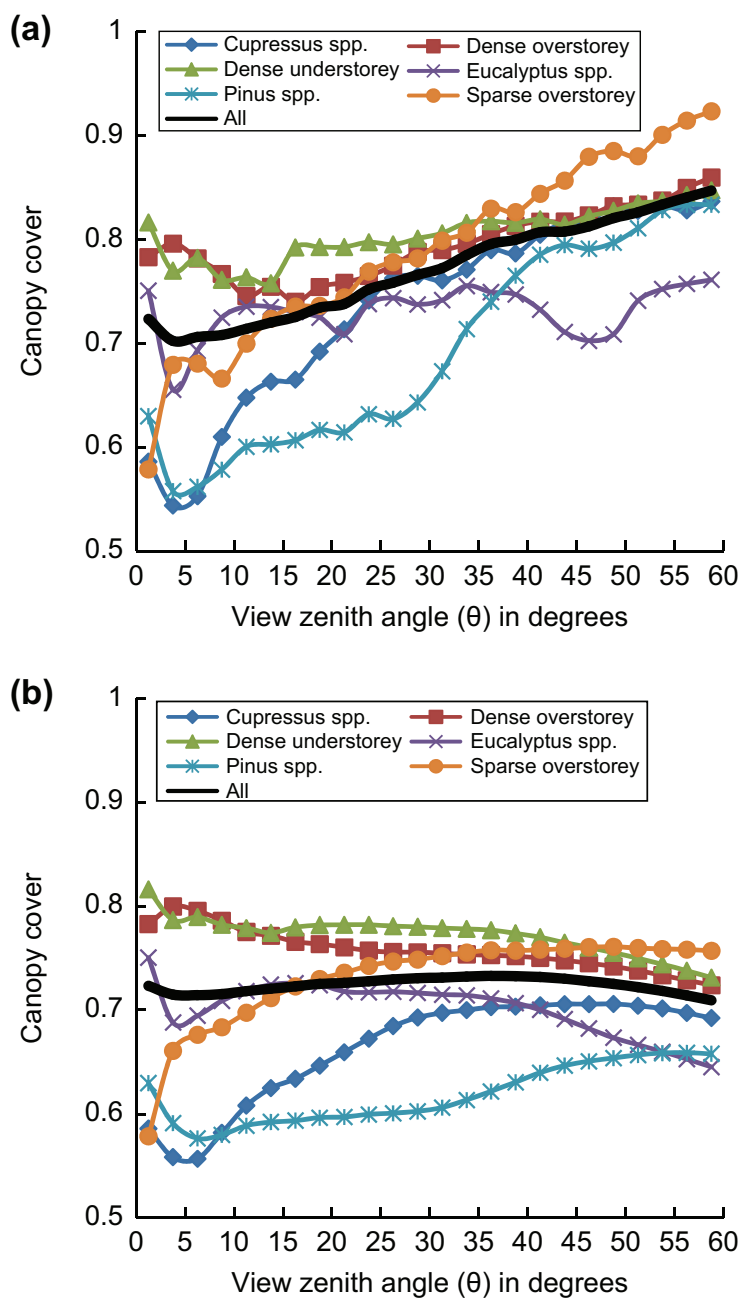

Figure 3. Canopy cover $(\mathrm{CaCo})$ estimated from hemispherical photography representing a large scale sampling strategy. (a) $\mathrm{CaCo}$ estimate at each zenith angle using the Eq. 2, and (b) CaCo estimate for the integral of various zenith angles ranging from $0-60^{\circ}$ using Eq. 3. 

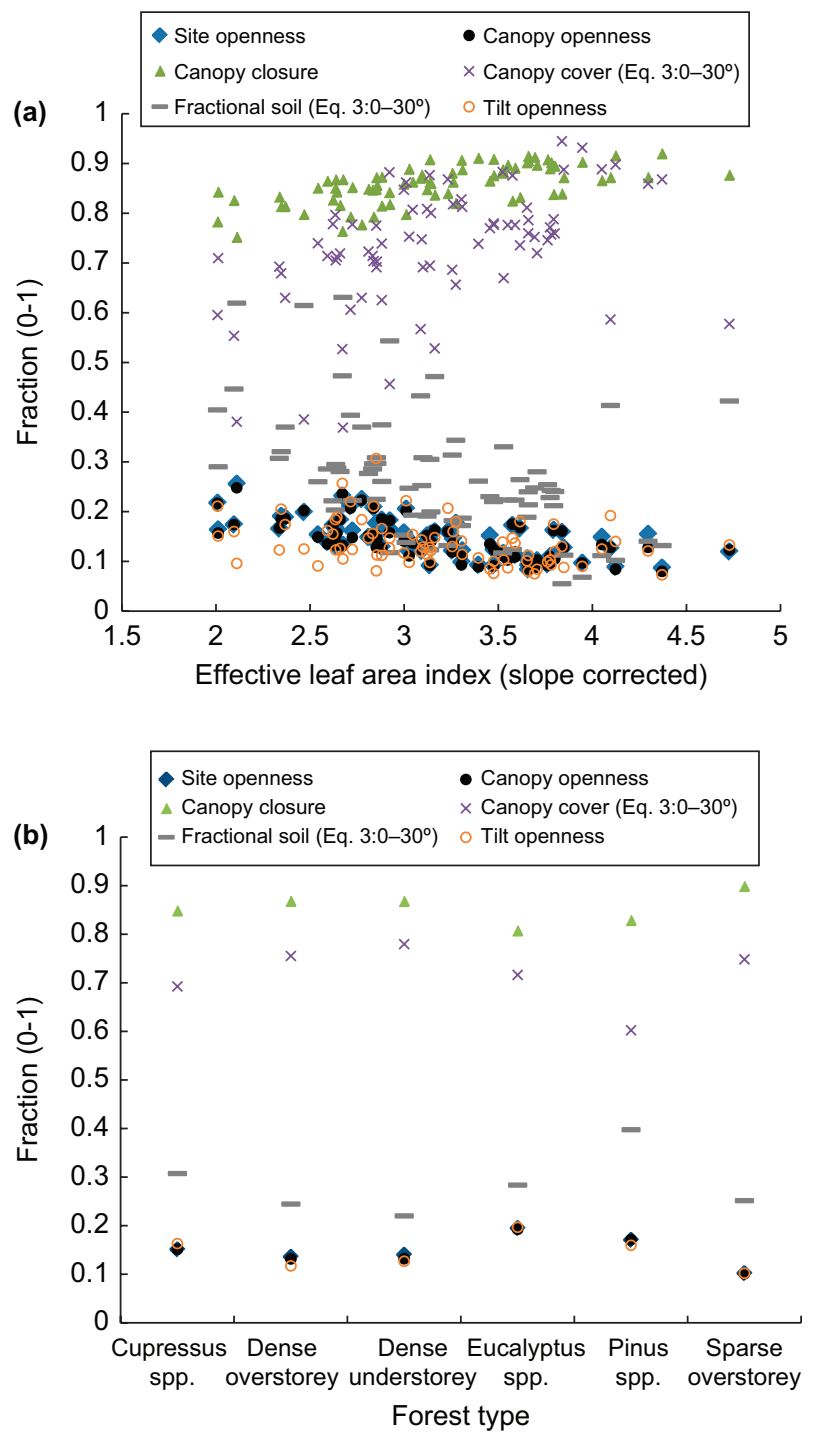

Figure 4. The fractional canopy element cover and openness measures plotted along the estimated leaf area index from individual photo sites (a), and averaged per forest type (b). Except tilt openness which was calculated from tilted acquisition, all the other measures were calculated from levelled acquisition.

to high overall density of the forests. However, the results in Fig. 4a show that there is a large discrepancy of fractional canopy element cover and openness measures at photo site level comparison.

Figure 3 and 4 answer two questions related with our objectives: 1$)$ can we get stable large scale canopy cover $(\mathrm{CaCo})$ estimates with few HP measurements, and 2) are there major discrepancies among various fractional canopy element cover and openness measures, and if yes, are there mathematically traceable relationships among these measures.

We proposed new sets of methods (Eq. 2, 3, 4) to answer the first question. Figure $3 \mathrm{~b}$ shows that the CaCo estimation becomes stable after zenith angle $30^{\circ}$. This suggests that either the zenith angle ranges between $0^{\circ}$ and $30^{\circ}$ or $30^{\circ}$ and $60^{\circ}$ can be used to achieve unbiased and stable $\mathrm{CaCo}$ estimates using Eq. 3. The latter range of zenith angles was also found to be the preferable hemisphere region to estimate LAI and canopy element clumping index due to several practical reasons (Leblanc et al. 2005) while also being close to theoretically preferable zenith regions (Gonsamo et al. 2010). Those zenith angles close to nadir are affected by sampling biases (by placing the HP sensor on open and unobstructed areas) and optical errors (e.g. strong forward sun scattering on lens) whereas, those close to the horizon are affected by sampling and optical errors such as: insufficient viewable $P_{0}$, coarse pixel resolutions, blocking from tree trunks, multiple scattering, lens vignetting, and blurring. We proposed Eq. 3 to circumvent the large amount of point based measurements required to achieve unbiased $\mathrm{CaCo}$ estimates (Johansson 1985, Jennings et al. 1999, Rautiainen et al. 2005) with an alternative less time consuming method. HP has not been commonly used to estimate $\mathrm{CaCo}$ because only few acquisitions (less than $12 \mathrm{HPs}$ ) are often taken per plot of various sizes. The traditional way to estimate $\mathrm{CaCo}$ from these few HPs relies on the use of Eq. 1 from $P_{0}$ near to nadir $\left(\theta<10^{\circ}\right)$. This results in biased $\mathrm{CaCo}$ estimate due to under sampling. However, Eq. 3 can be used with few HPs per plot to sample large areas with stable $\mathrm{CaCo}$ estimates from the zenith region between $30^{\circ}-60^{\circ}$ due to inclusion of large footprint with normalized $P_{0}$ to nadir view.

As expected, the nadir measures, i.e. CaCo and FS did not show 1:1 relationships with other hemispherical measures when compared at each photo site (Fig. 4a, Table 1). This is because the same value of $\mathrm{CaCo}$ (and its complement in a unity, FS) could correspond to various values of $\mathrm{CaCl}, \mathrm{CO}, \mathrm{SO}, \mathrm{TO}$ and $\mathrm{LAI}$, or vice versa, although the latter five parameters have shown statistically stronger relationships amongst themselves (Table 1). To answer the aforementioned question 2), various fractional canopy element cover or openness measures as presented in Fig. 4 and Table 1 cannot be regarded as directly equivalent. Except the two pairs, i.e. $\mathrm{CaCo}$ versus $\mathrm{FS}$ and $\mathrm{CaCl}$ versus $\mathrm{CO}$, there are no mathematically traceable relationships among other fractional canopy element cover and openness measures.

Table 1. Pearson correlation matrix among fractional canopy element cover and openness measures. Except between 'Tilt openness' versus 'Canopy cover' and 'Tilt openness' versus 'Fractional soil' all correlations are significant ( $p<0.001$, two-tailed t-test).

\begin{tabular}{|c|c|c|c|c|c|c|c|}
\hline & LAI & $\begin{array}{c}\text { Site } \\
\text { openness }\end{array}$ & $\begin{array}{l}\text { Canopy } \\
\text { openness }\end{array}$ & $\begin{array}{l}\text { Canopy } \\
\text { closure }\end{array}$ & $\begin{array}{l}\text { Canopy cover } \\
\left.\text { (Eq. 3: } 0-30^{\circ}\right) \\
\end{array}$ & $\begin{array}{l}\text { Fractional soil } \\
\left.\text { (Eq. 3: } 0-30^{\circ}\right)\end{array}$ & $\begin{array}{c}\text { Tilt } \\
\text { openness }\end{array}$ \\
\hline \multicolumn{8}{|l|}{ LAI } \\
\hline Site openness & -0.643 & & & & & & \\
\hline Canopy openness & -0.641 & 0.986 & & & & & \\
\hline Canopy closure & 0.641 & -0.986 & -1.000 & & & & \\
\hline Canopy cover (Eq. 3: 0-30) & 0.471 & -0.397 & -0.447 & 0.447 & & & \\
\hline Fractional soil (Eq. 3: 0-30 ) & -0.471 & 0.397 & 0.447 & -0.447 & -1.000 & & \\
\hline Tilt openness & -0.358 & 0.634 & 0.627 & -0.627 & -0.141 & 0.141 & \\
\hline
\end{tabular}




\section{Conclusion}

The definitions provided in this paper and results of the case study show that most of the fractional canopy element cover and openness measures represent physically different structural properties of vegetated ecosystems. Unfortunately, the majority of fractional canopy element covers and openness concepts are not mathematically traceable to one another. Although these measures have been in use for a long time by scientific, government and environmental communities, to the best of our knowledge this study represents the first attempt to comprehensively clarify and standardize the definitions for: canopy closure, canopy cover, canopy openness, crown closure, crown completeness, crown cover, crown porosity, site openness, and tilt openness. Previous studies have stressed the need for standardized concepts of canopy fractional cover and openness measures, however only provide definitions for few (Jennings et al. 1999, Rautiainen et al. 2005, Korhonen et al. 2006, Wilson 2011).

We have provided new methodologies to estimate fractional canopy element cover and openness measures based on the commonly available, inexpensive, and technologically advancing in situ instrument, hemispherical photography (HP), in order to sample large areas with the least possible bias, time and labour forces. Our experience with HP and literature survey suggests that often less than $12 \mathrm{HP}$ point samples are taken per plot of 400 or more $\mathrm{m}^{2}$ in contrast to 200-250 point measurements required for unbiased $\mathrm{CaCo}$ estimates. To this regard, Eq. 3 provides an alternative approach to estimate nadir direction metrics whilst covering a large sampling footprint. For CaCo estimates, being a popular canopy measure, we recommend the use of Eq. 3 with $P_{0}$ sampled from $30^{\circ}-60^{\circ}$ zenith angle ranges.

We believe that all of the presented metrics are functionally distinct. The $\mathrm{CaCo}$ and $\mathrm{CrCo}$ measures can be used to characterise forest overstorey conditions such as the dominance of site by arboreal trees, stand density, and species competition. Measures like $\mathrm{CaCl}, \mathrm{CO}$ and $\mathrm{SO}$ characterise the light regime and microclimate on the forest floor including understorey and the potential penetration of solar radiation into forest canopies. TO can be a useful measure to characterise the light regime in tropical forests growing on hilly terrains where light is a limiting factor due to persistent cloud cover and the diffuse radiation from surrounding forest and hills is a substantial source of solar radiation. Except TO, all other fractional canopy element cover and openness measures shall be estimated from levelled acquisition of hemispherical photographs. We recommend further studies in different ecosystems to validate the large scale fractional canopy element cover and openness estimation methods presented here. Also, we strongly recommend all future operational and scholarly reports to explicitly provide the standardised definitions of all canopy element cover and openness definitions used in the measurements.

Acknowledgements - We thank Tom Blom (IT Specialist, IT Dept, Univ. of Helsinki) for assistance with script programming and Lauri Korhonen for constructive comments in earlier version of the manuscript. This research was made possible by a TAITA project (<www.helsinki.fi/science/taita/index.html $>$ ) funded by the Academy of Finland. AG is financed partly by CIMO (Centre for
International Mobility), Dept of Geography of Univ. of Helsinki, and the Finnish Graduate School of Geography. We thank Nadine Nesbitt for language correction.

\section{References}

Avery, T. E. and Burkhart, H. E. 1994. Forest measurements, 4th ed. - McGraw-Hill.

Bréda, N. J. J. 2003. Ground-based measurements of leaf area index: a review of methods, instruments and current controversies. - J. Exp. Bot. 54: 2403-2417.

Bunnell, F. L. and Vales, D. J. 1990. Comparison of methods for estimating forest overstory cover: differences among techniques. - Can. J. For. Res. 20: 101-107.

Bunnell, F. L. et al. 1985. Trees and snow: the deposition of snow on the ground. A review and quantitative synthesis. - Victoria Research Paper no. IWIFR-17.

Campbell, G. S. and Norman, J. M. 1990. The description and measurement of plant canopy structure. - Cambridge Univ. Press.

Carreiras, J. M. B. et al. 2006. Estimation of tree canopy cover in evergreen oak woodlands using remote sensing. - For. Ecol. Manage. 223: 45-53.

FAO 2001. Global forest resources assessment 2000. - Main report, Food and Agriculture Organization of the United Nations.

Ganey, J. L. and Block, W. M. 1994. A comparison of two techniques for measuring canopy closure. - West. J. Appl. For. 9: 21-23.

Gonsamo, A. and Pellikka, P. 2008. Methodology comparison for slope correction in canopy leaf area index estimation using hemispherical photography. - For. Ecol. Manage. 256: 749-759.

Gonsamo, A. and Pellikka, P. 2009. The computation of foliage clumping index using hemispherical photography. - Agric. For. Meteorol. 149: 1781-1787.

Gonsamo, A. et al. 2010. Sampling gap fraction and size for estimating leaf area and clumping indices from hemispherical photographs. - Can. J. For. Res. 40: 1588-1603.

Gonsamo, A. et al. 2011a. Large-scale leaf area index inversion algorithms from high-resolution airborne imagery. - Int. J. Remote Sens. 32: 3897-3916.

Gonsamo, A. et al. 2011b. CIMES: A package of programs for determining canopy geometry and solar radiation regimes through hemispherical photographs. - Comput. Electron. Agric. 79: 207-215.

Hill, R. 1924. A lens for whole sky photographs. - Q. J. R. Meteor. Soc. 50: 277-235.

Jennings, S. B. et al. 1999. Assessing forest canopies and understorey illumination: canopy closure, canopy cover and other measures. - Forestry 72: 59-74.

Johansson, T. 1985. Estimating canopy density by the vertical tube method. - For. Ecol. Manage. 11: 139-144.

Kaartinen, H. et al. 2012. An international comparison of individual tree detection and extraction using airborne laser scanning. - Remote Sens. 4: 950-974.

Ko, D. et al. 2009. Canopy cover estimation in semiarid woodlands: comparison of field-based and remote sensing methods. - For. Sci. 55: 132-141.

Korhonen, L. et al. 2006. Estimation of forest canopy cover: a comparison of field measurement techniques. - Silva Fenn. 40: 577-588.

Korhonen L. et al. 2011. Airborne discrete-return LIDAR data in the estimation of vertical canopy cover, angular canopy closure and leaf area index. - Remote Sens. Environ. 115: 1065-1080.

Kucharik, C. J. et al. 1999. Characterization of radiation regimes in non random forest canopies: theory, measurements, and a simplified modeling approach. - Tree Physiol. 19: 695-706. 
Kulakowski, D. et al. 2011. The interacting effects of land use change, climate change and suppression of natural disturbances on landscape forest structure in the Swiss Alps. - Oikos 120: 216-225.

Kuusipalo, J. 1985. On the use of tree stand parameters in estimating light conditions below the canopy. - Silva Fenn. 19: 185-196.

Leblanc, S. G. et al. 2005. Methodology comparison for canopy structure parameters extraction from digital hemispherical photography in boreal forests. - Agric. For. Meteorol. 129: $187-207$

Leeuwen, M. and Nieuwenhuis, M. 2010. Retrieval of forest structural parameters using LiDAR remote sensing. - Eur. J. For. Res. 129: 749-770.

Lindberg, E. et al. 2012. Estimation of 3D vegetation structure from waveform and discrete return airborne laser scanning data. - Remote Sens. Environ. 118: 151-161.

Middelboe, A. L. and Binzer, T. 2004. Importance of canopy structure on photosynthesis in single- and multi-species assemblages of marine macroalgae. - Oikos 107: 422-432.

Monteith, J. L. and Unsworth, M. H. 1990. Principles of environmental physics, 2nd ed. - Edward Arnold.

Nuttle, T. 1997. Densiometer bias? Are we measuring the forest or the trees? - Wildlife Soc. B. 25: 610-611.

Pisek, J. et al. 2011. Estimating leaf inclination and G-function from levelled digital camera photography in broadleaf canopies. - Trees 25: 919-924.

Paletto, A. and V. Tosi. 2009. Forest canopy cover and canopy closure: comparison of assessment techniques. - Eur. J. For. Res. 128: 265-272.
Philip, M. S. 1994. Measuring trees and forests. - CAB International. Rautiainen, M. et al. 2005. Estimating canopy cover in Scots pine stands. - Silva Fenn. 39: 137-142.

Rich, P. M. 1990. Characterizing plant canopies with hemispherical photographs. - Remote Sens. Rev. 5: 13-29.

Rich, P. M. et al. 1993. Long-term study of solar radiation regimes in a tropical wet forest using quantum sensors and hemispherical photography. - Agric. For. Meteorol. 65: 107-127.

Ridler, T. W. and Calvard, S. 1978. Picture thresholding using an iterative selection method. - IEEE T Syst. Man Cyb. 8: 630-632.

Sarvas, R. 1954. Measurement of the crown closure of the stand. - Commun. Ins. For. Fenn. 41: 1-13.

Tabacchi, G. et al. 2007. Italian national forest inventory: methods, state of the project and future developments. - Proc. 7th Ann. For. Inventory and Anal. Symp.

Vales, D. J. and Bunnell, F. L. 1985. Comparison of methods for estimating forest overstory cover. - Integr. Wildlife Intensive For. Res. 20.

Walter, J. -M. N. and Torquebiau, E. F. 2000. The computation of forest leaf area index on slope using fish-eye sensors. - C. R. Acad. Sci. 323: 801-813.

Wilson, J. B. 2011. Cover plus: ways of measuring plant canopies and the terms used for them. - J. Veg. Sci. 22: 197-206.

Winter, S. et al. 2008. Possibilities for harmonizing national forest inventory data for use in forest biodiversity assessments. - Forestry 81: 33-44.

Yuan, Z. et al. 2012. What happens below the canopy? Direct and indirect influences of the dominant species on forest vertical layers. - Oikos 121: 1145-1153. 